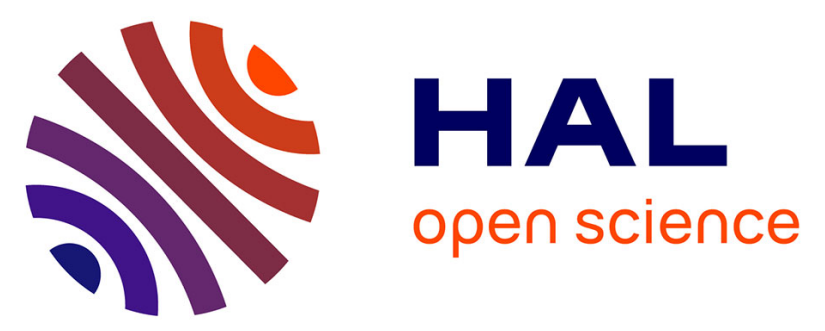

\title{
Clinical lessons learned in constitutional hypopituitarism from two decades of experience in a large international cohort
}

Nicolas Jullien, Alexandru Saveanu, Julia Vergier, Emeline Marquant, Marie

Helene Quentien, Frederic Castinetti, Noémie Galon-faure, Raja Brauner, Zinet Marrakchi Turki, Maité Tauber, et al.

\section{To cite this version:}

Nicolas Jullien, Alexandru Saveanu, Julia Vergier, Emeline Marquant, Marie Helene Quentien, et al. Clinical lessons learned in constitutional hypopituitarism from two decades of experience in a large international cohort. Clinical Endocrinology, 2021, 94 (2), pp.277-289. 10.1111/cen.14355 . hal-03225618

\section{HAL Id: hal-03225618 \\ https://hal-amu.archives-ouvertes.fr/hal-03225618}

Submitted on 12 May 2021

HAL is a multi-disciplinary open access archive for the deposit and dissemination of scientific research documents, whether they are published or not. The documents may come from teaching and research institutions in France or abroad, or from public or private research centers.
L'archive ouverte pluridisciplinaire HAL, est destinée au dépôt et à la diffusion de documents scientifiques de niveau recherche, publiés ou non, émanant des établissements d'enseignement et de recherche français ou étrangers, des laboratoires publics ou privés. 


\title{
Clinical lessons learned in constitutional hypopituitarism from two decades of experience in a large international cohort
}

\author{
Nicolas Jullien $^{1} \odot$ | Alexandru Saveanu ${ }^{2,3,4,5}$ | Julia Vergier ${ }^{6}$ | Emeline Marquant ${ }^{6}{ }^{6}$ | \\ Marie Helene Quentien $^{2}$ | Frederic Castinetti ${ }^{2,3,4}$ | | Noémie Galon-Faure ${ }^{7}$ | \\ Raja Brauner $^{8}$ | Zinet Marrakchi Turki ${ }^{9}$ | Maité Tauber ${ }^{10}$ | Mohamed El Kholy ${ }^{11}$ | \\ Agnès Linglart $^{12}$ | Patrice Rodien ${ }^{13}$ | Nora Soumeya Fedala ${ }^{14}$ | Ignacio Bergada ${ }^{15}$ | \\ Christine Cortet-Rudelli $^{16}$ | Michel Polak ${ }^{17}$ | Marc Nicolino ${ }^{18}$ | Chantal Stuckens ${ }^{19}$ | \\ Anne Barlier $^{2,3,4,5}$ | Thierry Brue ${ }^{2,3,4}$ | Rachel Reynaud ${ }^{2,4,6}$ | the Genhypopit Network

\footnotetext{
${ }^{1}$ Aix-Marseille Univ, CNRS, INP, Inst Neurophysiopathol, Marseille, France

${ }^{2}$ Aix-Marseille Université, Institut National de la Santé et de la Recherche Médicale (INSERM), U1251, Marseille Medical Genetics (MMG), Faculté des Sciences médicales et paramédicales, Institut Marseille Maladies Rares (MarMaRa), Marseille, France

${ }^{3}$ Department of Endocrinology, Centre de Référence des Maladies Rares de l'hypophyse HYPO, Hôpital de la Conception, Assistance Publique-Hôpitaux de Marseille (AP-HM), Marseille, France

${ }^{4}$ Centre de Référence des Maladies Rares de l'Hypophyse, CHU Conception, Assistance Publique-Hôpitaux de Marseille (APHM), Marseille, France

${ }^{5}$ Laboratory of Molecular Biology, CHU Conception, Assistance Publique-Hôpitaux de Marseille (APHM), Marseille, France

${ }^{6}$ Paediatric Endocrinology Unit, Department of Paediatrics, CHU Timone Enfants, Assistance Publique-Hôpitaux de Marseille (APHM), Marseille, France

${ }^{7}$ Department of Paediatrics, Centre Hospitalier du Pays d'Aix, Aix-En-Provence, France

${ }^{8}$ Fondation Ophtalmologique Adolphe de Rothschild and Université Paris Descartes, Paris, France

${ }^{9}$ National Institute of Nutrition, Tunis, Tunisia

${ }^{10}$ Paediatric Endocrinology Unit, Department of Paediatrics, Children Hospital, Toulouse University Hospital, Toulouse, France

${ }^{11}$ Department of Pediatrics, Ain Shams University, Cairo, Egypt

${ }^{12}$ Paediatric Endocrinology Unit, Department of Paediatrics, Assistance Publique-Hôpitaux de Paris (AP-HP), Le Kremlin-Bicêtre, France

${ }^{13}$ Endocrinology Department, Angers University Hospital, Angers, France

${ }^{14}$ Endocrinology Department, Bab El Oued University Hospital, Algiers, Algeria

${ }^{15}$ Children Hospital "Ricardo Gutierrez", Bueno-Aires, Argentina

${ }^{16}$ Department of Endocrinology and Diabetology, Lille University Hospital, Lille, France

${ }^{17}$ Paediatric Endocrinology Unit, Department of Paediatrics, Hôpital Universitaire Necker Enfants Malades, Assistance Publique-Hôpitaux de Paris (AP-HP), INSERM U1016, Institut IMAGINE, Paris, France

${ }^{18}$ Paediatric Endocrinology Unit, Department of Paediatrics, Hôpital Femme-Mère-Enfant, Hospices Civils de Lyon (HCL), Bron, France

${ }^{19}$ Department of Paediatrics, Hôpital Jeanne de Flandre, Lille University Hospital, Lille, France
}

Correspondence

Dr Julia Vergier, Hôpital Timone Enfants, 264 rue St Pierre, 13385 Marseille Cedex 05, France.

Email: julia.vergier@ap-hm.fr

Funding information

ANR GENOPAT 2008; Association pour le Développement de la Recherche Médicale au Centre Hospitalier Universitaire de Marseille

\section{Abstract}

Context: The international GENHYPOPIT network collects phenotypical data and screens genetic causes of non-acquired hypopituitarism.

Aims: To describe main phenotype patterns and their evolution through life.

Design: Patients were screened according to their phenotype for coding sequence variations in 8 genes: HESX1, LHX3, LHX4, PROP1, POU1F1, TBX19, OTX2 and PROKR2. 
Results: Among 1213 patients (1143 index cases), the age of diagnosis of hypopituitarism was congenital (24\%), in childhood (28\%), at puberty (32\%), in adulthood $(7.2 \%)$ or not available (8.8\%). Noteworthy, pituitary hormonal deficiencies kept on evolving during adulthood in 49 of patients. Growth Hormone deficiency (GHD) affected $85.8 \%$ of patients and was often the first diagnosed deficiency. AdrenoCorticoTropic Hormone deficiency rarely preceded GHD, but usually followed it by over 10 years. Pituitary Magnetic Resonance Imaging (MRI) abnormalities were common (79.7\%), with $39.4 \%$ pituitary stalk interruption syndrome (PSIS). The most frequently associated extrapituitary malformations were ophthalmological abnormalities (16.1\%). Prevalence of identified mutations was $7.3 \%$ of index cases (84/1143) and $29.5 \%$ in familial cases $(n=146)$. Genetic analysis in 449 patients without extrapituitary phenotype revealed 36 PROP1, 2 POU1F1 and 17 TBX19 mutations.

Conclusion: This large international cohort highlights atypical phenotypic presentation of constitutional hypopituitarism, such as post pubertal presentation or adult progression of hormonal deficiencies. These results justify long-term follow-up, and the need for systematic evaluation of associated abnormalities. Genetic defects were rarely identified, mainly PROP1 mutations in pure endocrine phenotypes.

\section{KEYWORDS}

ACTH deficiency, candidate gene approach, central hypothyroidism, congenital hypopituitarism, genetic screening, growth hormone deficiency, HESX1, LHX3, LHX4, PROP1, POU1F1, TBX19, OTX2, PROKR2, hypogonadotroph hypogonadism, Next-Generation Sequencing, ocular defect, panhypopituitarism, pituitary development, pituitary stalk interruption, transcription factor

\section{1 | INTRODUCTION}

Constitutional or primary hypopituitarism is defined by non-acquired anterior pituitary hormone deficiency, from single hormone deficit (as isolated GH deficiency [IGHD]) to combined pituitary hormone deficiencies (CPHD). These hormonal defects may be included in syndromic forms with extrapituitary malformations and thus usually be considered as a developmental defect. Pituitary development is orchestrated by a highly complex cascade of signalling molecules, mostly transcription or morphogenetic factors, through their specific temporal and spatial expressions. Disruption of this sequence of molecular events by genetic alterations of these factors may affect differentiation of one or more pituitary cell types and lead to hypopituitarism. ${ }^{1}$ Several defects of pituitary developmental factor genes (especially HESX1, LHX3, LHX4, PROP1, POU1F1, OTX2, PROKR2 and TBX19) have been associated with congenital hypopituitarism over the past decades. ${ }^{1}$ Genetic screening of these transcription factors using a phenotype-based strategy represents a rational way to identify aetiology of CPHD. However, defects in any of these genes have been found to date in a minority of such patients in national or international cohorts. ${ }^{2-10}$

The GENHYPOPIT network is a multicentre study in international paediatric and adult endocrinology centres. It was launched to screen pituitary transcription factor genes and enrolled patients with primary hypopituitarism over the past two decades. In 2006, we have presented an algorithm for genetic study in CPHD. ${ }^{6}$ This cohort had increased up to 1213 patients by December 2015, allowing description of genotypic and phenotypic characteristics in a much larger population. In this study, we focused on the outcome of the endocrine profile, associated phenotypes, and on comprehensive genetic results obtained from a phenotype-based genetic screening for 8 pituitary transcription factor genes, giving an unprecedented opportunity to describe the main features of constitutional hypopituitarism in a large consecutive international cohort of patients.

\section{2 | PATIENTS, MATERIAL AND METHODS}

\section{1 | Patients}

Between 1995 and 2015, 1213 patients recruited through the GENHYPOPIT network and presenting at least one primary anterior pituitary hormone deficiency were included, both paediatric and adult cases whatever the age or country of origin. Patients with acquired CPHD after tumour or surgery were excluded. Patients or parents of minor patients gave their written informed consent. A declaration has been made to the National Commission 
for Data Protection and Liberties (CNIL-France): $1991429 \vee 0$. Data were anonymously collected in a database declared to health authorities in accordance with local regulations. Investigators were prompted to send index case Deoxyribonucleic Acid (DNA) sample when other distinguishable aetiologies of pituitary deficiency had been ruled out by the routine anamnestic, clinical, biological and neuroradiological workup. The standardized survey used to collect relevant clinical, endocrine and radiological characteristics can be accessed at http://www.ap-hm.fr/defhy. Hormonal studies and cranial Magnetic Resonance Imaging (MRI) were performed in each referring medical centre as previously described. ${ }^{6}$ Panhypopituitarism was defined by the existence of 4 anterior pituitary deficiencies, regardless of the prolactin (PRL) status. Extrapituitary malformations were also reported. A familial case was defined by the presence of at least one other known case of constitutional hypopituitarism among the relatives of the index case.

\section{2 | Molecular analysis of candidate genes}

Genomic analysis of coding sequences of pituitary transcription factors genes such as HESX1, LHX3, LHX4, PROP1, POU1F1, TBX19, OTX2 and PROKR2 genes was performed by Sanger sequencing according to phenotypical data in accordance with the literature. All coding exons and exon-intron boundaries were amplified from genomic DNA by Polymerase Chain Reaction (PCR) using exonflanking primers. Primer sequences and detailed information about PCR or sequencing methods are available on demand. The genetic screening strategy suggested in 2006 was updated according to literature and presented in Figure S1. In case of consanguinity, genes usually involved in pure endocrine phenotype (PROP1, POU1F1) were also analysed even if extrapituitary abnormalities were observed.

\section{3 | Next-Generation Sequencing}

In order to validate our sequencing approach based on candidate genes, we performed Next-Generation Sequencing (NGS) analysis of the whole set of 8 genes for 189 patients randomly selected from the whole cohort using a QIAseq Targeted DNA Custom Panel (Qiagen) sequenced on NexSeq500 (Nexseq V2 Reagent Kit 300 cycles) (Illumina $($ )). Data issued from sequencing were further analysed and annotated using Biomedical Genomic Workbench v4.1.1. software (Qiagen). Coverage, for a depth exceeding 30X was $100 \%$ in the targeted regions (96 samples in a run).

All candidate variants found by Sanger sequencing or NGS were classified into five main categories using the American College of Medical Genetics and Genomics guidelines-pathogenic, likely pathogenic, variants of uncertain significance (VUS), likely benign, and benign. ${ }^{11}$ Sanger sequencing was performed to validate all variants categorized as pathogenic, likely pathogenic, or VUS.

\subsection{Statistical analysis}

Graphical representations and statistical analyses were made with $\mathrm{R}$ (3.2.2) and ggplot2 package (1.0.1). Univariate comparisons were performed using Fisher's exact test for qualitative data (results as the calculated Odd ratio [OR] and the $95 \%$ confidence interval), and Student or Welch $t$-test for quantitative data (a $p$-value $\leq .05$ was considered significant).

\section{3 | RESULTS}

\section{1 | Phenotypic description of the population}

DNA samples from 1213 patients belonging to 1143 unrelated families were collected. Sex ratio showed a male predominance $(M / F=1.48)$. Median age at the time of genetic analysis was 16.8 years (0-79). Considering the 1143 index cases, 146 patients (12.8\%) had a familial history of CPHD. Among 38 countries of origin, $72 \%$ of patients were European (63.7\% from France) and 10.1\% were from North Africa. Consanguinity was reported in 87 patients (7.2\% of overall cohort), including 50 patients from North Africa.

- Clinical features of hypopituitarism

Age at diagnosis: Hypopituitarism was diagnosed between 0 and 2 years in 24\% ( $n=291$ ) of all patients, between 2 and 10 years in $28 \%(n=340)$, between 10 and 20 years in $32 \%(n=388)$ and in adulthood in $7.2 \%$ (from 20 to 69 years) ( $n=87$ ). For the latter group, adult diagnosis means without any known clinical feature of deficiency during childhood or puberty; among them, 7 were familial cases: 4 index cases and 3 cases diagnosed after familial investigation.

Information about age at diagnosis was lacking for $8.8 \%$ ( $n=107)$. The presence of genital abnormalities in neonatal boys was not helpful for early diagnosis of hypopituitarism (see Figure S2). All anterior pituitary hormonal deficiencies were diagnosed significantly earlier in the pituitary stalk interruption syndrome (PSIS) group ( $p$ value $=8.10 \mathrm{E}-8$ in Welch two sample $t$-test).

Hormonal pattern: a quarter of the cohort $(26.4 \%, \mathrm{n}=320)$ presented isolated hormone deficiency, from whom $16.4 \%$ ( $n=199$ ) IGHD, all of them were associated with extrapituitary manifestation. Besides, 23.8\% ( $n=289$ ) had panhypopituitarism (see Table S1). Most patients were first diagnosed with two or more concomitant hormonal deficiencies, and $11.3 \%$ harboured panhypopituitarism before the age of 20. IGHD was the first event for 111 patients (9.2\%). The most frequent pituitary lineage defect was GHD, affecting $85.8 \%$ of patients, followed by thyrotropin deficiency (TSHD, 58.6\%), gonadotropin (LH/FSHD, 50.5\%) and corticotropin (AdrenoCorticoTropic deficiency $=$ ACTHD, 49.3\%). Ages at diagnosis of the latter three hormonal deficiencies compared to age at GHD diagnosis are presented on Figure 1A. Most of these deficiencies were discovered later in life (Figure 1A,B): close to puberty onset for LH/FSHD, and 10 years after GHD for ACTHD. Some patients harboured TSHD or 

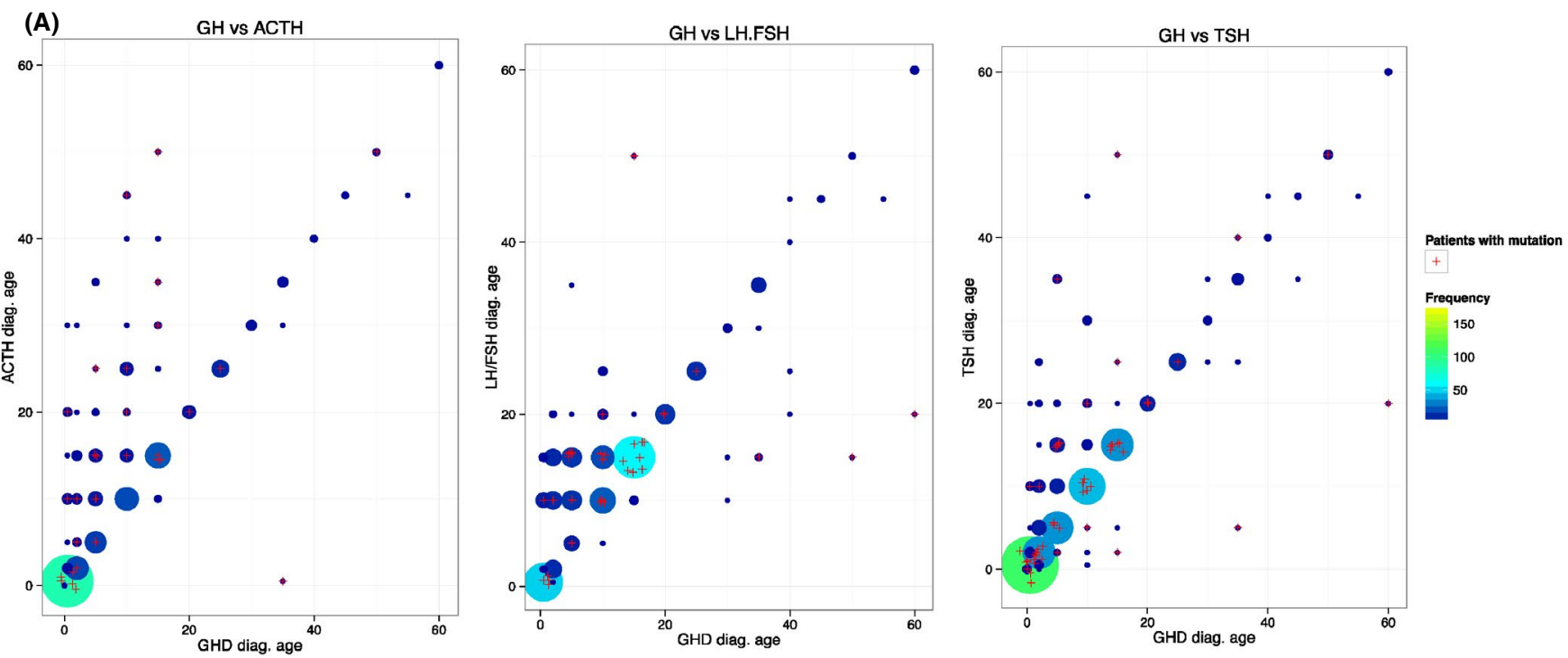

(B)

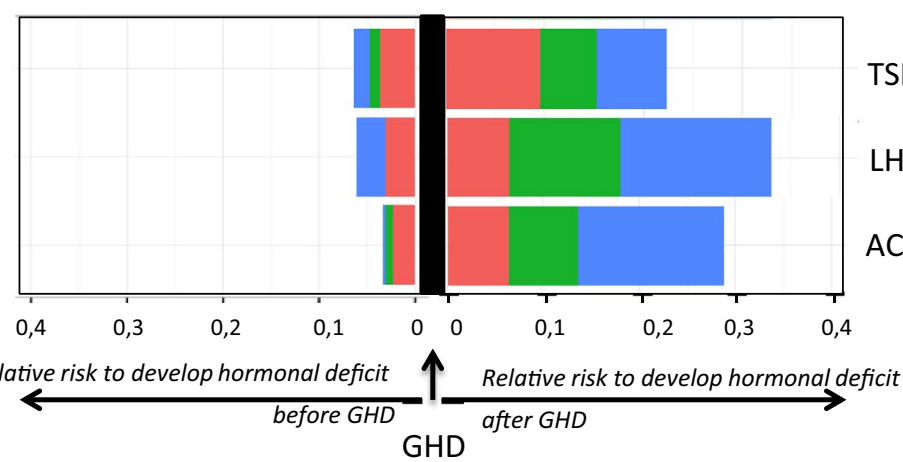

FIGURE 1 Age at diagnosis of hormonal deficiency. (A) Age at diagnosis of corticotrophin deficiency (ACTHD) (left), gonadotrophin deficiency (FSH/LHD) (middle) or thyrotropin deficiency (TSHD) (right) compared to age at diagnosis of growth hormone deficiency (GHD) (years). Circles are proportionally larger and coloured from blue to yellow according to increasing frequency of the considered deficiencies. Red cross: patient with causative gene defect. (B) Relative risk to develop hormonal deficit before (left part) or after (right part) diagnosis of GHD [Colour figure can be viewed at wileyonlinelibrary.com]

LH/FSHD first, but ACTHD rarely occurred before GHD (Figure 1B). Regardless existence of GHD, other pituitary hormonal deficiencies appeared at the same age in the all cohort. In patients with adult diagnosis, multiple deficiencies were frequent: GHD was found in $78.2 \%(68 / 87)$ of all patients, LH/FSHD = in 75.9\% (66/87), TSHD in $64.3 \%$ and ACTHD in $58.7 \%$.

- Cranial MRI and extrapituitary malformations (Table 1)

MRI results were available for 946 patients and were abnormal for $79.7 \%(n=754)$ of them: $61.9 \%(n=586)$ presented anterior pituitary anomalies, mostly aplasia or hypoplasia; $37.8 \%(n=358$ ) had ectopic posterior lobe (EPP) and $42 \%(n=397)$ had pituitary stalk abnormalities. PSIS was described in $39.4 \%$ of the cohort and $28.7 \%$ of adult patients. Other MRI findings are detailed in Table $1 \mathrm{~A}$. Regardless of frequent genital malformations mostly related to $\mathrm{LH} /$ FSHD and/or GHD, ophthalmological abnormalities were the most prevalent extrapituitary features associated with hypopituitarism ( $n=147$ patients). Other extrapituitary manifestations, mainly midline structural abnormalities and neuroradiological defects, are detailed in Table 1B.

\section{2 | Genetic findings}

Total prevalence of HESX1, LHX3, LHX4, PROP1, POU1F1, PROKR2, OTX2 or TBX19 gene defects was 7.3\% (84 mutations in 1143 index cases) Table 2. A greater prevalence was found in familial cases (29.5\% of index cases) versus sporadic ones (2.6\%) (OR = 10.8 [6.2$19.295 \% \mathrm{Cl}$ ) and in index cases born to consanguineous union (31.0\%) versus non-consanguineous (4.96\%) index cases (OR $=8.5$ [4.4-16.5 95\% CI]). Fewer mutations were found in PSIS patients (3.8\%) vs. those without PSIS (12.5\%) (OR = 3.6 [2.1-6.6 95\% CI]). Among patients with adulthood CPHD diagnosis, $5.7 \%$ genetic alterations were found.

- Mutations of transcription factors involved in early pituitary development 
TABLE 1 Phenotypic description of the cohort (clinical and radiological data)

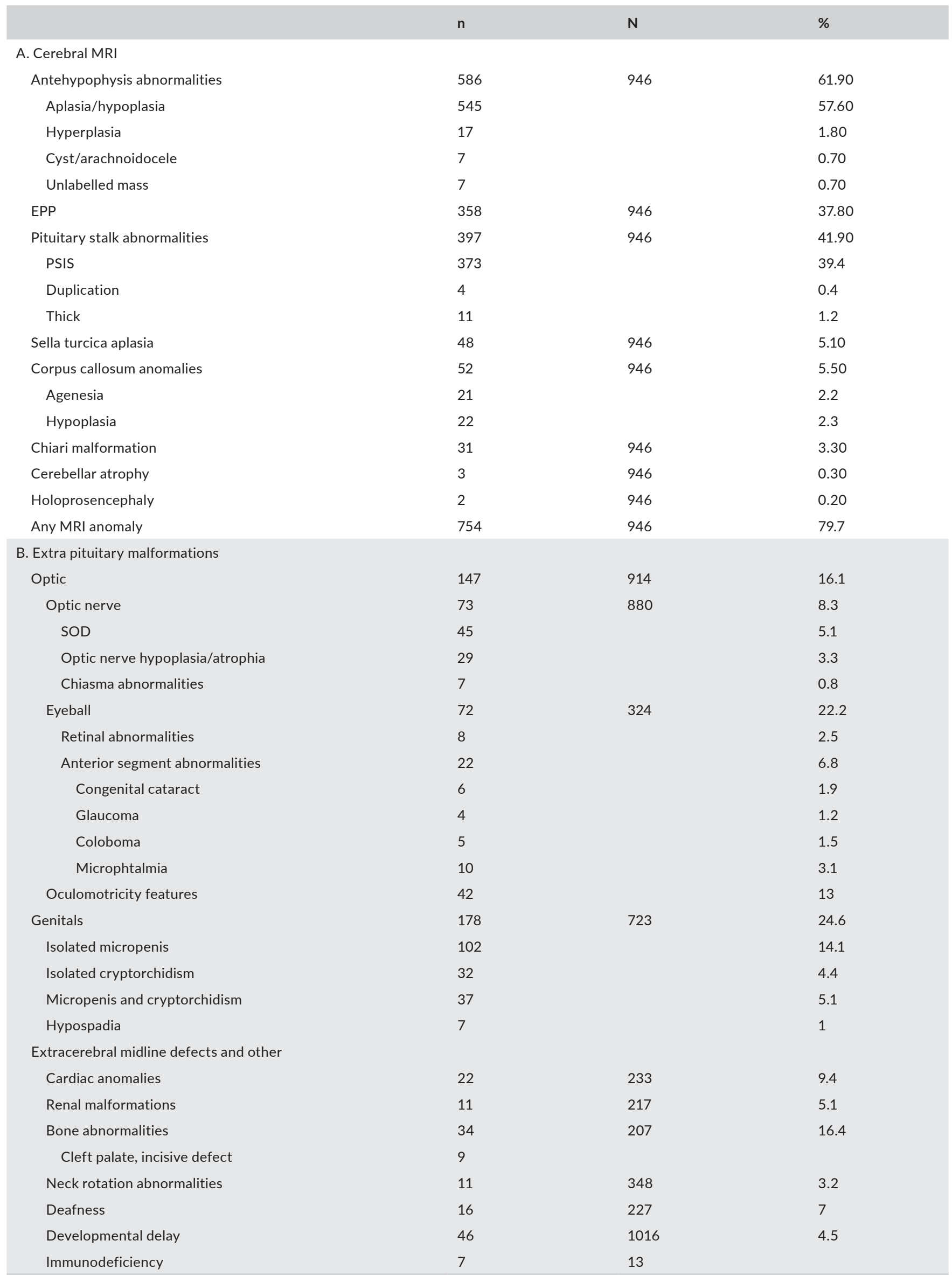

Abbreviations: $\mathrm{N}$, number of cases with this information in the database; $\mathrm{n}$, number of patients with this abnormality. 


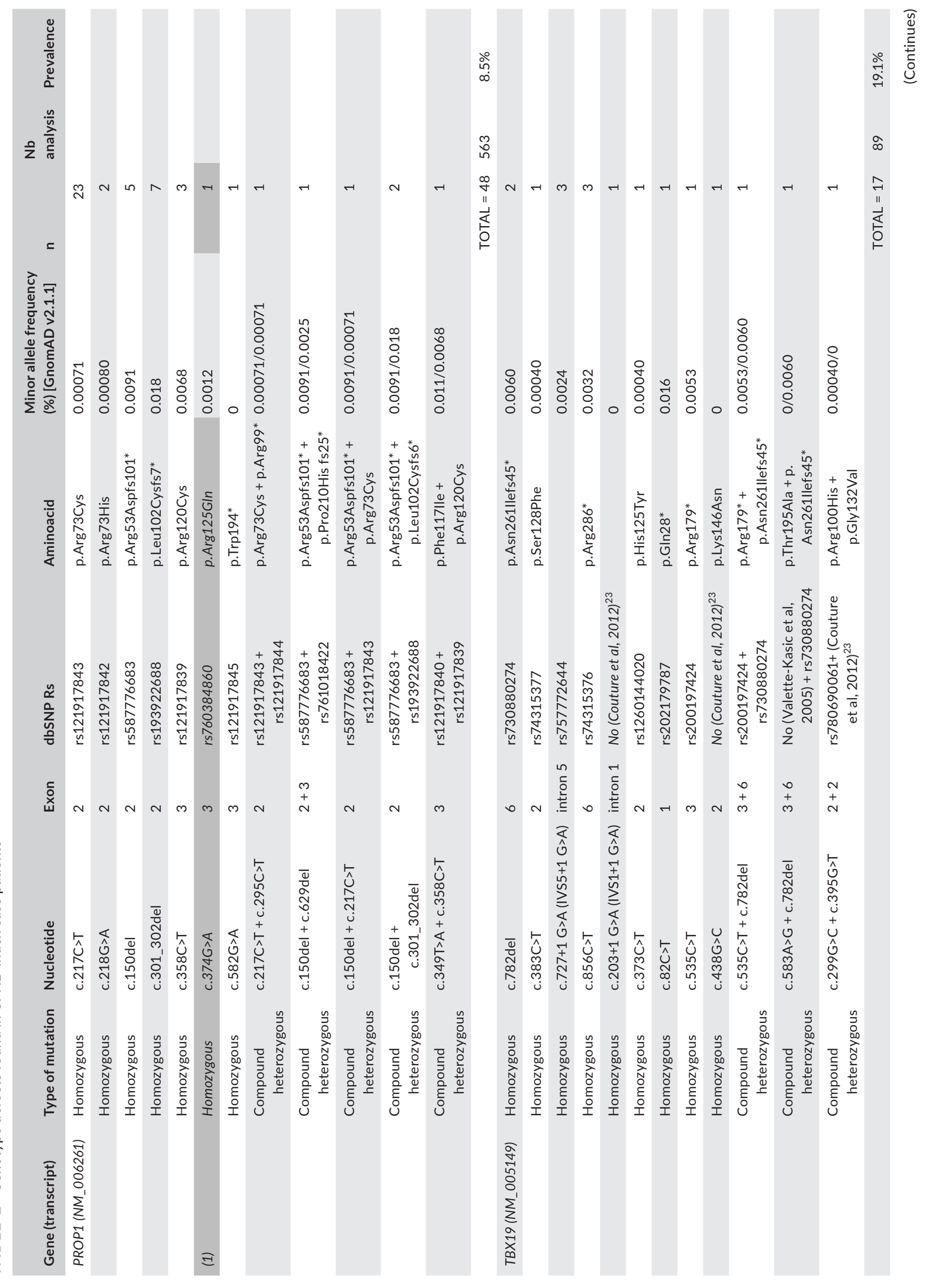




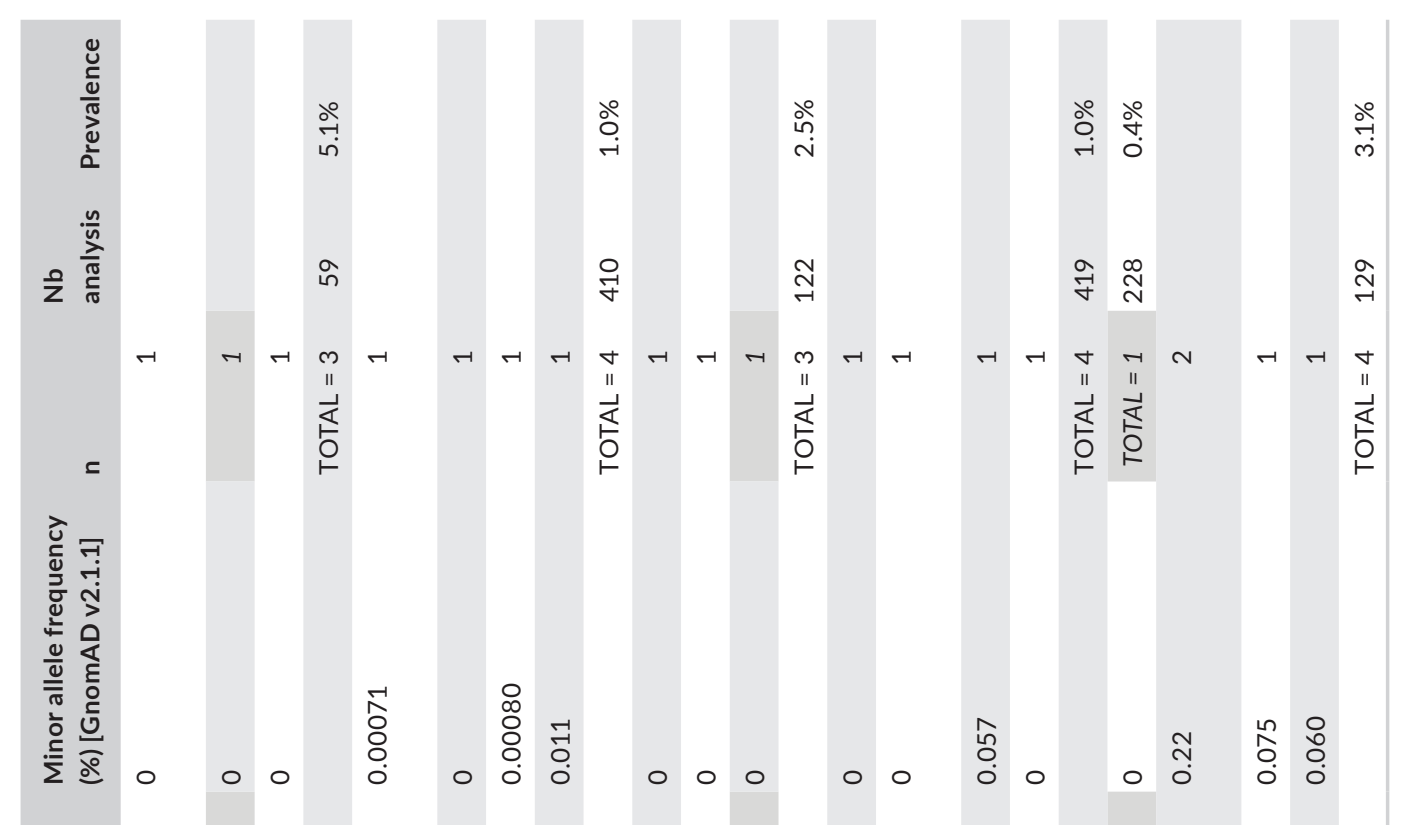

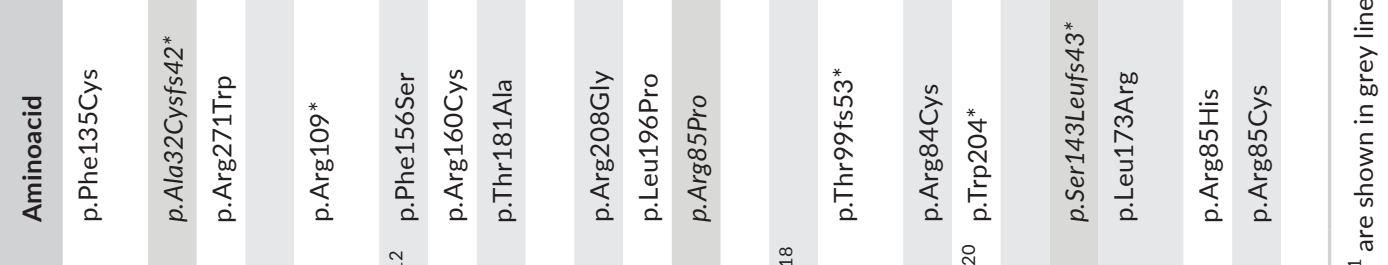

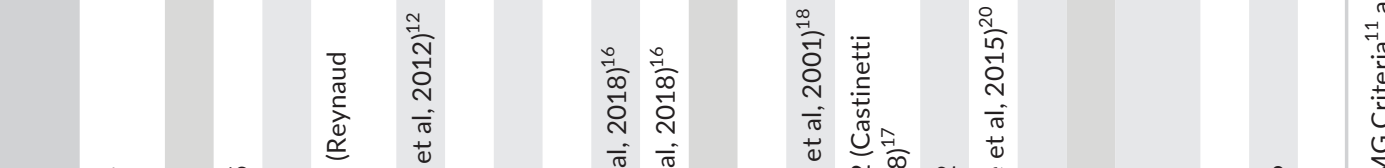

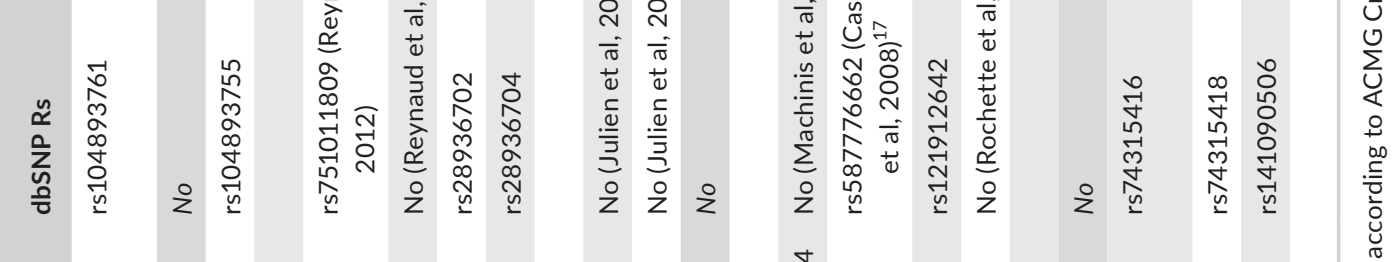

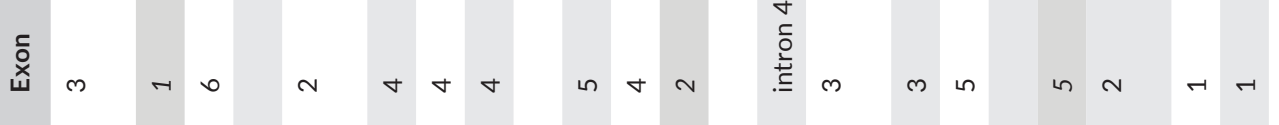

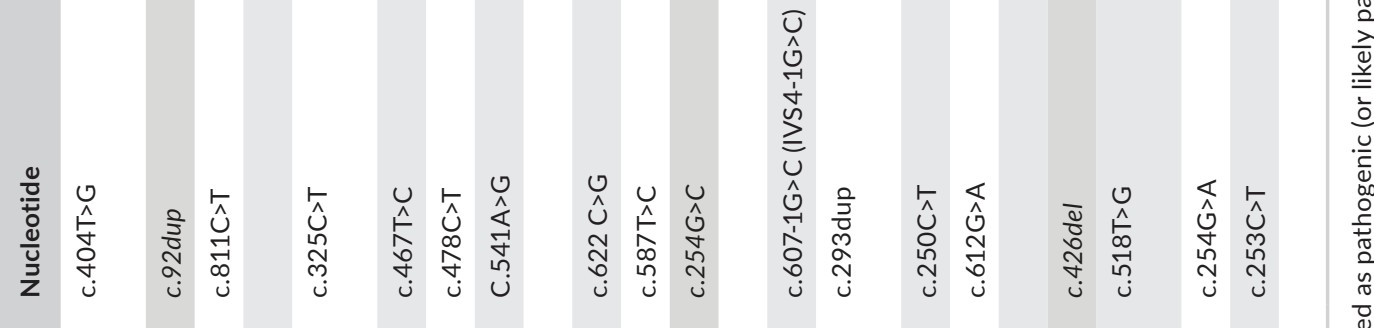

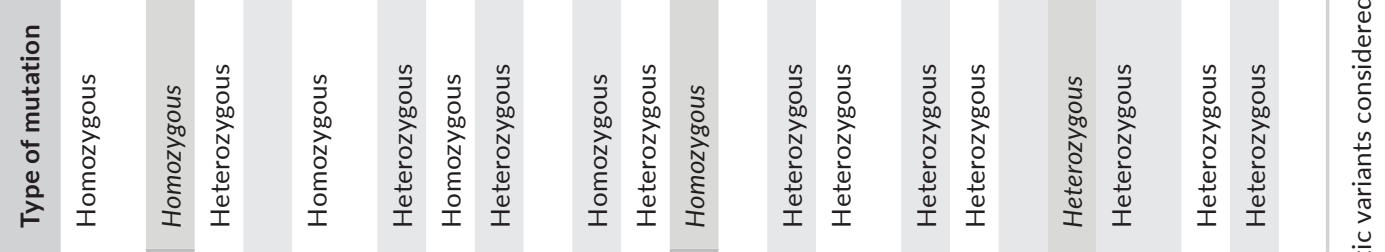

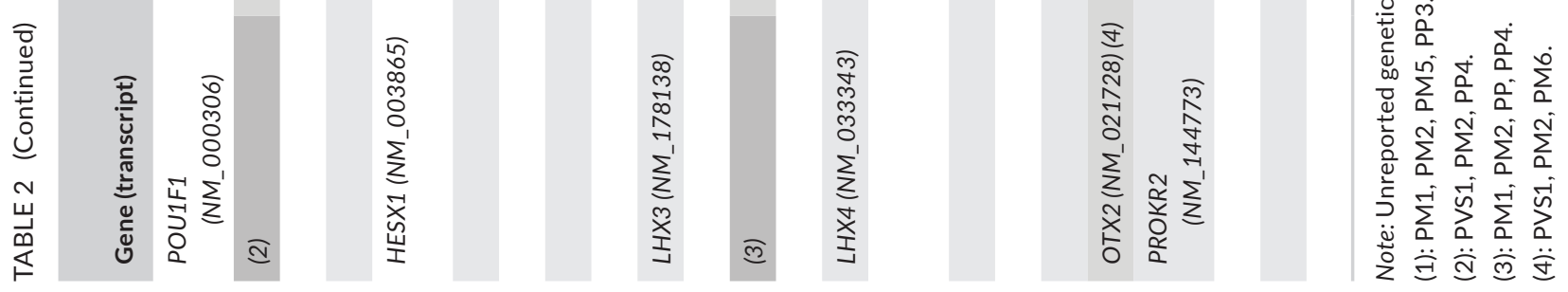


Four mutations in HESX1 were found in 1 sporadic and 3 familial cases with highly variable hormonal phenotypes: hypopituitarism ranged from IGHD to panhypopituitarism. All of them presented anterior pituitary hypoplasia associated with PSIS and/or EPP. These mutations have been previously reported: homozygous p.Arg109*, ${ }^{12}$ p.Arg160Cys ${ }^{13}$ and heterozygous p.Phe156Ser, ${ }^{14}$ and p.Thr181Ala. ${ }^{15}$ Interestingly, the clinical feature of the latter was found with heterozygous status in a 60-yr-old French woman presenting sporadic CPHD (GHD, TSHD and LH/FSHD), anterior pituitary hypoplasia and EPP. For both heterozygous mutations, previous in vitro studies ${ }^{14,15}$ suggested a dominant-negative effect; however, penetrance was incomplete.

Three mutations of $L H X 3$ were found. Two of them were recently published, with in vitro analysis, by our team. ${ }^{16}$ The first one was a girl born to consanguineous parents from Iran presenting with neonatal CPHD, corpus callosum agenesis and retinal dystrophy; she harboured homozygous p.Arg208Gly mutation and both asymptomatic parents showed heterozygous status for this mutation. The second one was an Italian male patient presenting with neonatal CPHD associated with partial hearing loss who carried a heterozygous p.Leu196Pro variant, inherited from his apparently healthy mother. ${ }^{16}$ The third patient harboured neonatal CPHD, anterior pituitary hypoplasia and a homozygous p.Arg85Pro mutation, situated in the LIM1 domain of the protein, with in silico evidence for a damaging effect on protein function.

LHX4 analysis revealed four previously published gene defects (17, 19, 20): p.Thr99Asnfs53*,17 one intronic point mutation involving the splice-acceptor site preceding exon 5 (c.607-1G>C), ${ }^{18}$ p.Arg84 Cys $^{19}$ and p.Trp204*. ${ }^{20}$ Pituitary phenotypes were various forms of CPHD including at least GHD and TSHD, always associated with PSIS. Associated extrapituitary disorders were Chiari malformation, corpus callosum hypoplasia or sella turcica aplasia. As already published, all LHX4 mutations were inherited, penetrance was incomplete and phenotype was variable.

One new OTX2 gene defect on exon 5 (c.426del, p.Ser143Leufs*43) was found in a 16 -yr-old Algerian boy presenting IGHD and bilateral microphthalmia (analysis carried out on 10 patients with microphthalmia, ie 14.3\%). Cerebral MRI showed bilateral optic nerve atrophy and EPP. The variant was 'de novo' as his parents did not express it. It was classified as pathogenic according to ACGM criteria (Richards et al, 2015). See legend Table 2.

Three heterozygous genetic alterations of PROKR2 were identified: p.Arg85His, p.Arg85Cys and p.Leu173Arg. The latter was found in two apparently unrelated patients. The first patient, previously published, ${ }^{14}$ showed childhood TSHD, pubertal FSHD/LHD and late GHD-ACTHD at 35 years associated with PSIS and arachnoidocele. The second one, unpublished, had ACTHD and TSHD without any MRI anomaly. All PROKR2 variants were inherited from one apparently healthy parent. Penetrance is incomplete for these variants, and pathogenicity of heterozygous PROKR2 variants in absence of clear dominant-negative effect is still debated. ${ }^{21}$

- Mutations of transcription factors involved in late cell type differentiation
PROP1 homozygous or compound heterozygous mutations were identified in 48 index cases. Familial history of CPHD was present in 31 patients (64.6\%), 24 were native from North Africa (50\%) and 17 born from consanguineous unions (35.4\%). Age at diagnosis of each anterior pituitary deficiency according to each PROP1 genetic alteration is reported in Figure S2: deficiencies were diagnosed earlier for patients harbouring R73C mutation (Two sample $t$-test $p$ value $=.035$ ) compared to others. The outcome of endocrine profile through life showed highly variable delay between first and latest diagnosed hormonal deficiency, with the occurrence of late ACTHD, sometimes almost 40 years later. Pituitary size abnormalities included hypoplasia (48.8\%) and hyperplasia (11.6\%). Syndromic forms were notified for 12 patients (25\%) which is surprising since PROP1 mutations do not on the whole result in extrapituitary abnormalities; 7 of them were born from consanguineous unions which may lead to distinct conditions. Syndromic manifestations were PSIS and/or EPP $(n=6)$, ocular abnormalities ( $n=2$, glaucoma or nystagmus), cardiac malformation $(n=1)$, deafness $(n=2)$, renal malformation ( $n=1)$ and developmental delay $(n=1)$. One novel homozygous variant, p.Arg125Gln, was revealed by primary amenorrhoea in a 15-yr-old girl with GHD, LH/FSHD and TSHD. In silico studies suggested a pathogenic effect of this variant modifying the homeodomain and affecting codon 125, crucial for the protein's function. ${ }^{22}$ Four index cases were diagnosed with CPHD after the age of 20. There was one male patient who reached a final height within the range of target height, with TSHD and LH/FSHD at 25 years followed by GHD and ACTHD diagnosed at 65 years. Three females ( 2 from Tunisia and 1 from Greece, all in remote areas) were diagnosed with panhypopituitarism at first investigation; their final height was $140 \mathrm{~cm}, 145 \mathrm{~cm}$ and $125 \mathrm{~cm}$.

In the cohort of CPHD without ACTHD and LH/FSHD whatever the age ( $n=59), 3(5.1 \%)$ variations were found in POU1F1 (Table 2), including two familial consanguineous cases and one sporadic case. One homozygous indel variant c.92dup (p.Ala32Cysfs42*) was found in an Algerian patient born from consanguineous union, presenting GHD, TSHD, PRL deficiency and anterior pituitary aplasia. In the 6 patients presenting CPHD without ACTHD during infancy, one harboured POU1F1 mutation (16.7\%). In the postpubertal pure CPHD group ( $n=23$ ) with spontaneous puberty and normal corticotropin function, the prevalence of POU1F1 defects increased up to $8.7 \%(2 / 23)$.

Overall, 17 TBX19 homozygous or compound heterozygous mutations were found, including 2 familial cases and 3 born to consanguineous unions. All patients but one presented isolated ACTHD ${ }^{23}$ without extrapituitary features; 16 of them were diagnosed in the neonatal period, one at the age of two. One patient harboured transient neonatal GHD and TSHD that were finally reversible at 2 years.

\subsection{Next-Generation Sequencing findings}

To confirm the relevance of the candidate gene approach to screen our large cohort of 1143 index cases, 189 DNA samples 
from random patients from this cohort were analysed by massive parallel sequencing using a library including the 8 genes of this study. The same mutations were found without any other additional mutation in this set of 8 genes according to ACMG guidelines (data not shown).

\section{4 | DISCUSSION}

In this study, we report the largest phenotype analysis and genotype screening published to date in constitutional hypopituitarism, performed in 1213 patients recruited through the international GENHYPOPIT network. This work provided phenotypic information including adulthood diagnosis, and clinical presentation associated with defects found in 8 genes involved in pituitary deficiencies.

Over the past decades, identification of mutations in pituitary transcription factor genes improved the understanding of mechanisms involved in constitutional hypopituitarism. ${ }^{1}$ However, genetic counselling remains a challenge due to variable phenotypes with incomplete penetrance and wide spectrum of anterior pituitary dysfunctions ranging from isolated deficiency to evolving panhypopituitarism. To date, several cohorts of patients with hypopituitarism have been reported from national registries ${ }^{3-5,8-10,24}$ or international studies. ${ }^{7}$ However, few provided detailed phenotypic description of CPHD patients. ${ }^{4,7,8}$ This study represents the most complete picture currently available of this rare disease in a multicentre and heterogeneous cohort. Limitations of the study may include the retrospective nature of the data and lacking information, such as neuroimaging presentation missing for $20.3 \%$ of patients. About phenotypic description, patients were recruited in different medical centres from various countries with healthcare access inequalities. Difficulty in accessing health care may lead to delay in diagnosis of hypopituitarism or extrapituitary anomalies. About genetic analysis, we did not look for large duplications/ deletions including SOX3, neither for GLI2 mutations in PSIS patients. Besides, for GLI2 we had no patient with polydactyly. ${ }^{25}$ However, this large cohort gives an overview of the main phenotypes associated with gene defects and their evolution overtime.

\subsection{Hormonal presentation and age of diagnosis}

In our study, the most frequent and earlier hormonal deficiency was GHD which is similar to the single-centre follow-up study of Cerbone et $\mathrm{al}^{26}$ However, $14.2 \%$ of all patients did not harbour GHD, in contrast with other series where this deficiency is the main inclusion criteria for genetic testing with a prevalence up to $96 \%$ $100 \%{ }^{9}$ Diagnosis was mostly established during the neonatal period, as in the study of Cerbone et al, ${ }^{26}$ or the second decade of life, that is around the age of normal puberty onset. Few data are available on age of onset of pituitary deficiencies, with 2 other studies describing similar patterns. ${ }^{4,5}$ Importantly, in some patients, an earlier diagnosis may have been possible taking into account specific features of neonatal hypopituitarism such as prolonged jaundice or hypoglycaemia, or presence of extrapituitary birth defects. ${ }^{27}$ Noteworthy, about $7.2 \%$ of our patients were diagnosed in adulthood, a feature that had never been reported with such a prevalence in other studies, underlining the need for long-term follow-up in such patients. Correa et al reported an adult-onset phenotype in a 19-yr-old female patient with a PROKR2 mutation, panhypopituitarism and delayed diabetes insipidus. ${ }^{9}$ Main risk factors for progression from IGHD to CPHD include identified organic aetiology, midline brain and optic nerves abnormalities. ${ }^{28}$ Importantly, genetic diagnosis provides medical caretakers with highly relevant information on the endocrine outcome: for instance, patients with PROP1 mutations will need to have induced puberty and require clinical and hormonal follow-up of corticotroph function, to avoid potentially life-threatening complications, ${ }^{29}$ while patients with POU1F1 mutations are not at risk of developing corticotroph or gonadotroph deficiency.

\section{2 | Extrapituitary associated features}

After genital malformations mainly linked to hormonal deficiencies, ophthalmological abnormalities were the most frequent extrapituitary features reported (16.1\%, Table 1 ), including evident eyeball malformations but also other features requiring specific ophthalmological examination (glaucoma, congenital cataract and retinal dystrophy). Other extrapituitary features such as renal malformations and deafness were more rarely observed. Identification of hearing loss appears to be helpful in genetic diagnosis as reported by Rajab et al, as $20 \%$ of CPHD deaf patients screened for LHX3 harboured a defect in this gene. ${ }^{30}$ Ophthalmological examination and audiogram should thus be performed in each patient with congenital hypopituitarism. Immunodeficiency has also been previously described. ${ }^{31}$

\section{3 | MRI findings}

Phenotypic evolution towards complete CPHD is correlated to the presence of hypothalamo-pituitary region morphological abnormalities and other brain malformations. ${ }^{32,33}$ Cerbone et al found that specific MRI abnormalities predispose to a higher risk of early-onset pituitary deficiencies. ${ }^{26}$ In our cohort, PSIS was the most frequent hypothalamo-pituitary abnormality (39.4\%) with a lower prevalence than previously reported in the United Kingdom $(48.1 \%)^{7}$ or in Japan (70\%), ${ }^{2}$ suggesting differences in genetic background or recruitment patterns. These data emphasize the crucial role of cerebral imaging in optimizing initial diagnosis.

\section{4 | Genetic findings}

Genetic analysis revealed an overall incidence of $7.3 \%$ of mutations in index cases of this cohort and $5.7 \%$ in the subgroup of 
patients with adult diagnosis of hypopituitarism. Most cases thus remain unsolved. ${ }^{33,34}$ Massive parallel sequencing including 8 candidate genes did not identify more mutations than targeted Sanger sequencing based on a phenotypic decisional tree. And an update algorithm has been suggested based upon clinical features (Figure S1), this is an evolutionary approach that will include new candidate genes and CNV data. The strongest predictor of identified genetic defect was family history of hypopituitarism: genetic alterations prevalence in sporadic cases was rare in our experience (4.4\%) and that of others $(1.1 \%-6 \%)^{4,7,35}$ while it increased up to $29.5 \%$ in familial cases.

Overall, mutations of genes encoding transcription factors involved in early pituitary development were relatively rare; some were associated with syndromic CPHD, with clinical heterogeneity and poor phenotype-genotype correlation. Mutations in HESX1 or LHX4 represented rare causes of hypopituitarism associated with PSIS and/or EPP (2\%), as reported in the literature. ${ }^{12,17}$ Prevalence of LHX3 mutations was greater among patients with deafness, but no mutation was found in the 8 patients harbouring neck rotation abnormalities unlike previous reports. ${ }^{36}$ OTX2 involvement was found by others in more than $10 \%$ of cases with eyeball malformations ${ }^{37}$ in agreement with our results, as it plays a key role in ophthalmological development. $^{1}$

Non-syndromic hypopituitarism in neonates was mainly linked to PROP1, POU1F1 and TBX19 mutations. Even if TBX19 is a main gene involved in neonatal $A C T H D,{ }^{38}$ we reported a neonatal ACTHD case with transient GHD and TSHD as previously described once. ${ }^{39}$ This suggests that after infancy and corticotroph substitution, reevaluation of somatotroph and thyrotroph functions should be discussed.

In non-syndromic CPHD, PROP1 mutations remained the most frequently identified ( $8.6 \%$ of patients analysed) as described before ${ }^{24}$; this prevalence was greater in consanguineous patients because of recessive inheritance. ${ }^{3,7}$ Diagnosis of hormonal deficiencies occurred mainly in childhood for GHD and throughout life for TSHD; 25\% had adulthood LH/FSHD, sometimes revealing PROP1 mutations after 20 years as previously reported. ${ }^{40}$ In this setting, ACTHD appeared later in life, with only $20 \%$ diagnosed at 20 years and up to $50 \%$ at 30 years, highlighting the importance of careful monitoring of corticotroph function into adult life in agreement with literature. ${ }^{41}$

In non-syndromic forms, the prevalence of POU1F1 gene defects increased up to $16.7 \%$ in neonates with normal corticotroph function, and up to $8.7 \%$ in the postpubertal population without LH/FSHD and ACTHD. We describe for the first time PROP1 or POU1F1 mutations (in 12 and 1 cases, respectively) in patients harbouring extrapituitary features, most of them born from consanguineous unions, which increases the risk of abnormalities linked to other unrelated autosomal recessive disorders. Therefore, PROP1 and POU1F1 analysis should not be excluded in consanguineous CPHD patients with syndromic forms and extrapituitary phenotypes.
According to Blum et al, significant indicators of a mutation were combined pituitary hormone deficiency, greater patient-parent height difference (SDS), low GH peak and young age. ${ }^{34}$

In case of negative results in patients with CPHD, genetic analysis must be extended using whole exome or whole genome sequencing in further studies. ${ }^{25}$ Further NGS approaches recently led to gene discovery and emergence of guidelines for variants assigning causality.

In conclusion, our observations of atypical phenotypic presentations such as adult-onset and evolving forms support the need for a lifetime monitoring of pituitary function to optimize patient care in constitutional hypopituitarism. ${ }^{42}$ Identification of mutations responsible for constitutional hypopituitarism remains a rare occurrence; more than $90 \%$ of cases remaining unexplained. Although of help for genetic counselling or for anticipating endocrine phenotype in some patients, identification of mutations responsible for constitutional hypopituitarism remains a rare occurrence; more than $90 \%$ of cases remaining unexplained. These findings underline the need for further research into epigenetic and other alternative mechanisms.

\section{ACKNOWLEDGEMENTS}

The authors are indebted to all clinicians (see list of Genhypopit investigators) who sent clinical information and blood samples for genetic studies, and to all patients and their families for accepting to take part in this research project. We thank Morgane Pertuit and Sylvie Palazzolo for expert technical support and Bérengère Saliba-Serre for her help in statistical analyses. This work was supported by a grant from the ANR GENOPAT 2008 "MDPHD ", and by the 'Association pour le Développement de la Recherche Médicale au Centre Hospitalier Universitaire de Marseille' (ADEREM).

\section{DISCLOSURE STATEMENT}

The authors have nothing to disclose.

\section{DATA AVAILABILITY STATEMENT}

The data that support the findings of this study are available from the corresponding author upon reasonable request.

\section{ORCID}

Nicolas Jullien (D) https://orcid.org/0000-0001-8273-2106

Emeline Marquant (D) https://orcid.org/0000-0002-9094-7382

Frederic Castinetti (D) https://orcid.org/0000-0002-1808-8800

\section{REFERENCES}

1. Castinetti F, Reynaud R, Saveanu A, et al. MECHANISMS IN ENDOCRINOLOGY: an update in the genetic aetiologies of combined pituitary hormone deficiency. Eur J Endocrinol. 2016;174(6):R2 39-R247.

2. Dateki S, Fukami M, Uematsu A, et al. Mutation and gene copy number analyses of six pituitary transcription factor genes in 71 patients with combined pituitary hormone deficiency: identification 
of a single patient with LHX4 deletion. J Clin Endocrinol Metab. 2010;95(8):4043-4047.

3. Lemos MC, Gomes L, Bastos M, et al. PROP1 gene analysis in Portuguese patients with combined pituitary hormone deficiency. Clin Endocrinol (Oxf). 2006;65(4):479-485.

4. McLennan K, Jeske Y, Cotterill A, et al. Combined pituitary hormone deficiency in Australian children: clinical and genetic correlates. Clin Endocrinol (Oxf). 2003;58(6):785-794.

5. Rainbow LA, Rees SA, Shaikh MG, et al. Mutation analysis of POUF-1, PROP-1 and HESX-1 show low frequency of mutations in children with sporadic forms of combined pituitary hormone deficiency and septo-optic dysplasia. Clin Endocrinol (Oxf). 2005;62(2):163-168.

6. Reynaud R, Gueydan M, Saveanu A, et al. Genetic screening of combined pituitary hormone deficiency: experience in 195 patients. J Clin Endocrinol Metab. 2006;91(9):3329-3336.

7. Turton JPG, Mehta A, Raza J, et al. Mutations within the transcription factor PROP1 are rare in a cohort of patients with sporadic combined pituitary hormone deficiency (CPHD). Clin Endocrinol (Oxf). 2005;63(1):10-18.

8. Vieira TC, Boldarine VT, Abucham J. Molecular analysis of PROP1, PIT1, HESX1, LHX3, and LHX4 shows high frequency of PROP1 mutations in patients with familial forms of combined pituitary hormone deficiency. Arq Bras Endocrinol Metabol. 2007;51(7):1097-1103.

9. Correa FA, Trarbach EB, Tusset C, et al. FGFR1 and PROKR2 rare variants found in patients with combined pituitary hormone deficiencies. Endocr Connect. 2015;4(2):100-107.

10. Fritez N, Sobrier M-L, Iraqi H, et al. Molecular screening of a large cohort of Moroccan patients with congenital hypopituitarism. Clin Endocrinol (Oxf). 2015;82(6):876-884.

11. Richards S, Aziz N, Bale S, et al. Standards and guidelines for the interpretation of sequence variants: a joint consensus recommendation of the American College of Medical Genetics and Genomics and the Association for Molecular Pathology. Genet Med. 2015;17(5):405-424.

12. Reynaud R, Albarel F, Saveanu A, et al. Pituitary stalk interruption syndrome in 83 patients: novel HESX1 mutation and severe hormonal prognosis in malformative forms. Eur J Endocrinol. 2011;164(4):457-465

13. Brickman JM, Clements M, Tyrell R, et al. Molecular effects of novel mutations in Hesx1/HESX1 associated with human pituitary disorders. Development. 2001;128(24):5189-5199.

14. Reynaud R, Jayakody SA, Monnier C, et al. PROKR2 variants in multiple hypopituitarism with pituitary stalk interruption. J Clin Endocrinol Metab. 2012;97(6):E1068-1073.

15. Thomas PQ, Dattani MT, Brickman JM, et al. Heterozygous HESX1 mutations associated with isolated congenital pituitary hypoplasia and septo-optic dysplasia. Hum Mol Genet. 2001;10(1):39-45.

16. Jullien N, Romanet $P$, Philippon $M$, et al. Heterozygous LHX3 mutations may lead to a mild phenotype of combined pituitary hormone deficiency. Eur J Hum Genet. 2019;27(2):216-225.

17. Castinetti F, Saveanu A, Reynaud R, et al. A novel dysfunctional LHX4 mutation with high phenotypical variability in patients with hypopituitarism. J Clin Endocrinol Metab. 2008;93(7):2790-2799.

18. Machinis K, Pantel J, Netchine I, et al. Syndromic short stature in patients with a germline mutation in the LIM homeobox LHX4. Am J Hum Genet. 2001;69(5):961-968.

19. Pfaeffle RW, Hunter CS, Savage JJ, et al. Three novel missense mutations within the LHX4 gene are associated with variable pituitary hormone deficiencies. J Clin Endocrinol Metab. 2008;93(3):1062-1071.

20. Rochette C, Jullien N, Saveanu A, et al. Identifying the deleterious effect of rare LHX4 allelic variants, a challenging issue. PLoS One. 2015;10(5):e0126648.

21. Cox KH, Oliveira LMB, Plummer L, et al. Modeling mutant/wildtype interactions to ascertain pathogenicity of PROKR2 missense variants in patients with isolated GnRH deficiency. Hum Mol Genet. 2018;27(2):338-350
22. Kelberman D, Turton JPG, Woods KS, et al. Molecular analysis of novel PROP1 mutations associated with combined pituitary hormone deficiency (CPHD). Clin Endocrinol (Oxf). 2009;70(1):96-103.

23. Couture C, Saveanu A, Barlier A, et al. Phenotypic homogeneity and genotypic variability in a large series of congenital isolated ACTHdeficiency patients with TPIT gene mutations. J Clin Endocrinol Metab. 2012;97(3):E486-E495.

24. De Rienzo F, Mellone S, Bellone S, et al. Frequency of genetic defects in combined pituitary hormone deficiency: a systematic review and analysis of a multicentre Italian cohort. Clin Endocrinol (Oxf). 2015;83(6):849-860.

25. Fang Q, George AS, Brinkmeier ML, et al. Genetics of combined pituitary hormone deficiency: roadmap into the genome era. Endocr Rev. 2016;37:636-675.

26. Cerbone M, Güemes M, Wade A, Improda N, Dattani M. Endocrine morbidity in midline brain defects: differences between septooptic dysplasia and related disorders. EClinicalMedicine. 2020;19: 100224.

27. Dutta P, Gupta P, Singh P, et al. Extra-pituitary birth defects may predict diagnosis of congenital hypopituitarism in a short child. $J$ Assoc Physicians India. 2015;63(8):28-36.

28. Cerbone M, Dattani MT. Progression from isolated growth hormone deficiency to combined pituitary hormone deficiency. Growth Horm IGF Res. 2017;37:19-25.

29. Pekic S, Doknic M, Miljic D, et al. Case seminar: a young female with acute hyponatremia and a sellar mass. Endocrine. 2011;40(3):325-331.

30. Rajab A, Kelberman D, de Castro SCP, et al. Novel mutations in LHX3 are associated with hypopituitarism and sensorineural hearing loss. Hum Mol Genet. 2008;17(14):2150-2159.

31. Quentien MH, Delemer B, Papadimitriou DT, et al. Deficit in anterior pituitary function and variable immune deficiency (DAVID) in children presenting with adrenocorticotropin deficiency and severe infections. J Clin Endocrinol Metab. 2012;97(1):E121-E128.

32. Iorgi ND, Allegri AEM, Napoli F, et al. The use of neuroimaging for assessing disorders of pituitary development. Clin Endocrinol (Oxf). 2012;76:161-176.

33. Gregory LC, Dattani MT. The molecular basis of congenital hypopituitarism and related disorders. J Clin Endocrinol Metab. 2019;105(6):e2103-e2120.

34. Blum WF, Klammt J, Amselem S, et al. Screening a large pediatric cohort with $\mathrm{GH}$ deficiency for mutations in genes regulating pituitary development and GH secretion: frequencies, phenotypes and growth outcomes. EBioMedicine. 2018;1(36):390-400.

35. Takagi M, Ishii T, Inokuchi M, et al. Gradual loss of ACTH due to a novel mutation in LHX4: comprehensive mutation screening in Japanese patients with congenital hypopituitarism. PLoS One. 2012;7(9):e46008

36. Pfaeffle RW, Savage JJ, Hunter CS, et al. Four novel mutations of the LHX3 gene cause combined pituitary hormone deficiencies with or without limited neck rotation. J Clin Endocrinol Metab. 2007;92(5):1909-1919.

37. Schilter KF, Schneider A, Bardakjian T, et al. OTX2 microphthalmia syndrome: four novel mutations and delineation of a phenotype. Clin Genet. 2011;79(2):158-168.

38. Patti G, Guzzeti C, Di lorgi N, et al. Central adrenal insufficiency in children and adolescents. Best Pract Res Clin Endocrinol Metab. 2018;32:425-444.

39. McEachern R, Drouin J, Metherell L, Huot C, Van Vliet G, Deal C. Severe cortisol deficiency associated with reversible growth hormone deficiency in two infants: what is the link? J Clin Endocrinol Metab. 2011;96(9):2670-2674.

40. Reynaud R, Barlier A, Vallette-Kasic S, et al. An uncommon phenotype with familial central hypogonadism caused by a novel PROP1 gene mutant truncated in the transactivation domain. J Clin Endocrinol Metab. 2005;90(8):4880-4887. 
41. Reynaud R, Chadli-Chaieb M, Vallette-Kasic S, et al. A familial form of congenital hypopituitarism due to a PROP1 mutation in a large kindred: phenotypic and in vitro functional studies. J Clin Endocrinol Metab. 2004;89(11):5779-5786.

42. Brue T, Saveanu A, Jullien N, et al. Lessons from monogenic causes of growth hormone deficiency. Ann Endocrinol (Paris). 2017;78(2):77-79. 


\section{APPENDIX 1}

\section{Genhypopit Investigators (in alphabetical order of country/city of} respective institutions and name)

Dr Fedala Nora, Algiers, Algeria; Dr Bessahraoui Mimouna, Oran, Algeria; Pr Bergada Ignacio, Buenos aires, Argentina; Pr Bruno Oscar, Buenos aires, Argentina; Dr Revencu Nicole, Brussels, Belgium; Dr Van Pottelberg Inge, Ghent, Belgium; Dr Destree Anne, Gosselies, Belgium; Dr Maystadt Isabelle, Gosselies, Belgium; Pr Beckers Albert, Liege, Belgium; Dr Valette Sophie, Montreal, Canada; Dr Sirrs Sandra, Vancouver, Canada; Pr Jorgensen Jens Otto Lunde, Aarhus, Denmark; Pr El Kholy Mohamed, Cairo, Egypt; Dr Artigas Merce,Pamplona, Spain; Dr Bony-Trifunovic Helene, Amiens, France; Pr Desailloud Rachel, Amiens, France; Pr Coutant Régis, Angers, France; Dr Illouz Frederic, Angers, France; Pr Rodien Patrice, Angers, France; Pr Rohmer Vincent, Angers, France; Dr Wright Catherine, Annecyn France; Dr Joubert Florence, Avignon, France; Dr Latil-Plat Françoise, Avignon, France; Dr Tizeggaghine Abdallah, Avignon, France; Dr Winiszewski Patrice. Belfort, France; Pr Barat Pascal, Bordeaux, France; Dr Cammas Benoit, Bordeaux, France; Dr Cazabat Laure, Boulogne, France; Pr Kerlan Véronique, Brest, France; Dr Sonnet Emmanuel, Brest, France; Dr Teissier Raphaël, Brest, France; Pr Borson-Chazot Françoise, Bron, France; Dr Brac de la Perrière Aude, Bron, France; Dr Bretones Patricia, Bron, France; Dr Raybaud Christine, Bron France; Pr Nicolino Marc, Bron France; Pr Pugeat Michel, Bron France; Pr Raverot Gerald, Bron France; Pr Kottler Marie-Laure, Caen, France; Pr Reznik Yves, Caen, France; Dr Buffin Arnaud, Chambéry, France; Dr Carla Hélène, Clermont-Ferrand, France; Pr Tauveron Igor, ClermontFerrand, France; Dr Ben Signor Candace, Dijon, France; Dr Loeuille Guy André, Dunkerque, France; Dr Russo Michel, Fontainebleau, France; Dr Spitéri Anne, Grenoble, France; Pr Chanson Philippe Le Kremlin-Bicêtre France; Pr Linglart Agnès, Le Kremlin-Bicêtre, France; Dr Rothenbuhler Anya, Le Kremlin-Bicêtre, France; Pr Young Jacques Le Kremlin-Bicêtre, France; Dr Stuckens Chantal, Lille, France; Dr Cortet-Rudelli Christine, Lille, France; Dr Weil Jacques, Lille, France; Pr Dewailly Didier, Lille, France; Dr Vantyghem Marie-Christine, Lille, France; Pr Wemeau Jean-Louis, Lille, France; Pr Archambeaud Francoise, Limoges, France; Pr Lienhardt Anne, Limoges, France; Pr Teissier Marie-Pierre, Limoges, France; Dr Albarel Frederique, Marseille, France; Pr Brue Thierry, Marseille, France; Pr Philip Nicole, Marseille, rance; Dr Fabre-Brue Catherine, Marseille, France; Dr Morange Isabelle, Marseille, France; Dr Nicolino Christine, Marseille, France; Dr Sigaudy Sabine, Marseille,
France; Pr Valero Rene, Marseille, France; Pr Barlier Anne, Marseille, France; Pr Castinetti Frederic, Marseille, France; Dr Caherec Anne, Martigues, France; Dr Jeandel Claire, Montpellier, France; Dr Fedou Christine, Montpellier, France; Dr Raingeard Isabelle, Montpellier, France; Pr Sultan Charles, Montpellier, France; Dr Martel Christine, Morlaix, France; Dr Baron-Joly Sandrine, Nantes, France; Pr Polak Michel, Necker, France; Dr Baechler Sadoul Elisabeth, Nice, France; Dr Brucker Davis Françoise, Nice, France; Dr Gastaud Frederique, Nice, France; Pr Fénichel Patrick, Nice, France; Dr Hieronimus Sylvie, Nice, France; Dr Hoflack Marie, Nice, France; Pr Sadoul Jean Louis, Nice, France; Dr Wagner Kathy, Nice, France; Dr Guedj Anne-Marie, Nîmes, France; Dr Ventura Valérie, Nîmes, France; Dr Emy Philippe, Orléans, France; Dr Barrande Marie-Gaëlle, Orléans, France; Pr Amselem Serge, Paris, France; Pr Brauner Raja, Paris, France; Dr Beltrand Jacques, Paris, France; Pr Bouchard Philippe, Paris, France; Pr Carel Jean-Claude, Paris, France; Pr Christin-Maitre Sophie, Paris, France; Dr Zenaty Delphine, Paris, France; Dr Cessans Christine, Poitiers, France; Pr Delemer Brigitte, Reims, France; Dr Souchon Pierre-François, Reims, France; Dr De la Rochebrochard Céline, Rennes, France; Dr Castanet Mireille, Rouen, France; Dr Pigeon-Kherchiche Patricia, Saint Denis de la réunion, France; Dr Richard Odile, Saint-Étienne, France; Dr Prieur Fabienne, Saint-Étienne, France; Pr Pinget Michel, Strasbourg, France; Dr Chabrier Gerard, Strasbourg, France; Dr Soskin Sylvie, Strasbourg, France; Dr Crea Thérèse, Thionville, France; Pr Caron Philippe,Toulouse, France; Dr Edouard Thomas, Toulouse, France; Dr Oliver Isabelle, Toulouse, France; Dr Pienkowski Catherine, Toulouse, France; Pr Tauber Maïté, Toulouse, France; Dr PepinDonat Myriam, Tours, France; Pr Leheup Bruno, Vandœuvre les Nancy, France; Dr Normand Isabelle, Vienne, France; Dr Andrikoula Maria, Ioannina, Greece; Dr Radetti Giorgio, Bolzano, Italia; Dr Tiziano Danielo, Rome, Italia; Dr Fabretto Antonella,Trieste, Italia; Pr Miyata Ichiro, Tokyo, Japan; Dr Tumiene Birute, Vilnius, Lituania; Dr Alsaker Heier, Oslo, Norway; Dr De vroede Monique, Utrecht, The Netherlands; Dr Smigiel Robert, Wrocław, Poland; Dr Bridges Nicola, London, UK; Dr Frances Elmslie, London, UK; Dr Johnson Diana,Sheffield, UK; Dr Robertson Lisa,Sheffield, UK; Pr Popovic Vera, Belgrade, Serbia; Pr Pfeifer Misa, Ljubljana, Slovenia; Dr Filipsson Helena, Göteborg, Sweden; Dr Rieubland Claudine, Bern, Sweden; Dr Ranza Emmanuelle, Geneva, Switzerland; Dr Kaffel Nourreddine, Sfax, Tunisia; Pr Chaieb Larbi, Sousse, Tunisia; Dr Lamine-Chtioui Faïza, Tunis, Tunisia; Pr Turki Zinet, Tunis, Tunisia; Dr Evliyaoglu Olca, Ankara, Turkey; Dr Aksu Oguzhan, Isparta, Turkey. 